\title{
The Linguistic Functions and Educational Implications of Silence in Pinter's The Dumb Waiter
}

\author{
Asst. Prof. Dr. Wiaam A. Albayati, University of Kufa/ Faculty of Languages, \\ Weam.albayati@uokufa.edu.iq \\ Asst. Prof Dr. Azhar Hussain Ubied Abbas, University of Kufa/ Faculty of Arts, \\ azhar.abbas@uokufa.edu.iq
}

\begin{abstract}
Though silence means a complete absence of audible sound, it is in no way related to absolute lack of communication. While speaking, people put smaller boundaries in between small chunks of their talk in an attempt to follow up larger ones. They could be among syllables, words, or elements in terms of phonology, semantics, or syntax respectively, with the goal of maintaining some social relations, in terms of pragma- linguistics. Even in written texts, particularly in those of drama, silence can be employed to some extent in a way that necessitates a kind of investigation. Silence, then, seems to be a meaningful tool whether it is used within the verbal communication or in the absence of speech in non-verbal communication.

Hence, the present study aims at investigating the communicative functions of silence in Pinter's The Dumb Waiter, and showing the meanings of silence whether verbally or non-verbally used. Further, by using Jaworski's (2006) model of silence functions, it inspects the applicability of the three major language functions, ideational, interpersonal and textual, to silence as a tool for communication. It is, accordingly, hypothesized that Pinter employs the three functions in his play; the most employed function of them is the interpersonal. Silence, in addition, is used to reflect the 'power' of one character over the others and identifies the 'distance' between them. Thus, the comedy of menace, as Pinter calls it, is constructed.

The study has, eventually, proved that silence has the same significance and functions of language. It has also concluded that investigating silence in literature, specifically in drama, adds very much to the interpretation, understanding, and the teaching of it.
\end{abstract}

Keywords: Linguistic functions, Educational Implications, The Dumb, Waiter, Harold Pinter, and Silence Received: 07.12.2020 Accepted: 06.01.2021 Published: 02.02.2021

\section{INTRODUCTION}

Silence, as a constitutive element of human communication, does not refer to a complete missing or absence of language. However, linguists often do not pay attention to silence and its function in communication the way it deserves. Despite being a powerful means of communication which is often used by people without much thinking, silence is traditionally ignored except for certain cases in which silence only indicates the beginnings or ends among pieces of discourse, i. e, where a speaker ends a role in communication so that the other party starts. This could be due to the misconception that absence of speech means absence of communication. In fact, the more knowledge about its significance there is, the more interactants can be far better communicators or text readers. It helps communication with people of different psychological status for different purposes in order to establish various common grounds of understanding.

It is, hence, accordingly hypothesized here that (1)the lack of spoken language does not mean lack of communication receiving or delivering messages, (2) a great deal of silence is employed in speech and written texts to for the sake of communication, and (3) silence has certain communicative functions in Pinter's The Dumb Waiter

The present study is going to qualitatively examine the communicative functions of silence in Pinter's The Dumb Waiter with the aims of: (1) investigating silence, its communicative functions, (2) showing the way it is employed at different linguistic levels, and (3) examining the way silence communicatively functions in Pinter's The Dumb Waiter.

Adopting Jaworski's (2006) analysis of Halliday's (1978) three major functions of language, the study is intended to verify its hypotheses and achieve its goals by following the procedures of: (1) presenting a theoretical framework on silence and its functions, (2) following Jaworski's (2006:644) analysis concerning Halliday's (1978) ideational, interpersonal and textual functions of language (3) 
analyzing silence in Pinter's The Dumb Waiter, and (4) discussing the results and drawing conclusions out of the analysis. However, the study falls within the scope of silence and its linguistic functions with their employment in Pinter's The Dumb Waiter only. Therefore, it is hoped the study to be valuable for researchers interested in investigating both linguistic functions of silence and The Dumb Waiter.

\section{Silence}

\section{The Concept}

Silence, for Levinson (1983: 298-9), is the absence of speech and lack, whether relative or total, of audible sound. Analogously, it might refer to any absence of communication, even in media, other than speech. However, silence, with reference to nonverbal communication and spiritual connection, can be used as a total means of communication that, in a sense, refers to the no sounds uttered by anybody in any room and/or space. That is why McHoul (2006: 205) thinks silence in discourse refers back to a hidden 'meaning' that a historian or philosopher must find and interpret.

Hence, having different interpretations in different contexts, silence shows its role as a vital factor from different cultural perspectives and in several activities, such as rituals. Wardhaugh (2006: 218) instructively draws attention to some of the ways in which people communicate in the world by employing lack of talk, i.e. silence, as opposed to talk. Furthermore, the topic of silence has attracted many researchers.

In the field of law, for instance, depending on silence interpretation in legal contexts wherein a witness or suspect is questioned, Kurzon (1995, as cited in Nakane,2014, p. 165) identifies two types of silence: unintentional non-deliberate silence that has some psychological reasons like embarrassment, shyness or needing to conceal ignorance, and intentional deliberate silence that shows the addressee's attempt not to cooperate with the addresser; the latter is probable perceived negatively by the addressers, i.e., police officers. Furthermore, Kurzon (2006: 512) thinks that the accused's right of silence in the AngloAmerican legal context, has been investigated pragmatically for more than one reason. First, it is investigated in order to answer the question of what the accused means by being silent during police investigation. Second, it is investigated in terms of the comprehensibility of language communication and establishing silence as a field of research associated with plain language.

In linguistics, silence in communication has been regarded as an essential in communication as speech itself, despite being defined as "an absence of noise" (Paulston et al 2012: 158). Besides, for Fairclough (2015: 150), silence is a "weapon for the less powerful participant,...[and] a way of being noncommittal about what more powerful participants say". At various levels of discourse it is said to be able to "affect power relationships in communication" (Paulston, et al., 2012: 161).

However, silence, in the form of silent pauses, is carefully examined in the light of the rules of turn- taking; so, there is no answer, it is marked as "a violation of turn- taking rules" (Nakane, 2014: 166). As an inaudible sound, silence is a 'fully-fledged event' in a conversation and consequential for the ensuing talk (Schegloff, 2001: 239). Hence, silences gain their interactional significance from their 'sequential context' and their position there. A silence, for instance, where an utterance has not been brought to a possible end could often be taken not as a silence but mere a pause in the continuous turns of the speakers talking (Sacks et al. 1974: 715 in Schegloff: ibid). Meanwhile, not all silences following a turn's possible completion are equivalent; following a question, a silence may have different interpretations and results from a silence following an answer depending on structural or related empirical studies(ibid.).

\section{Linguistic Functions}

\section{Jensen's (1973)}

Jensen (1973: 249-50) discusses five functions of silence and assigns positive and negative values to each one; silence may have:

1. a linkage function when two people may be bound or separated by silence them as they may be sitting and only enjoying the company of each other via silence full of emotion versus moments of silence filled with anger, and frustration of someone who can feel the tension in the environment.

2. an affecting function when silence may cure or hurt over time. People, sometimes, need someone to be with, but without words, just to help heal a hurt instead of searching for words of mutual understanding and comfort.

3. a revelation function where silence either makes something to be known to a person in a selfexploration or it conceals information. In interaction, a question may lead someone to pause and stop talking since speakers giving their responses are seriously thinking of them. Alternatively, that pause could reflect that someone is unwilling to reveal emotions or things they are thinking about. 
4. a judgmental function where silence signals assent or acceptance and favor or, on the contrary, can disclose dissent and disfavor. Children who are asking for their parents' permission to do or have something, for instance, may receive silence to be either a guarded permission or clear refusal for that request.

5. an activating function as silence may indicate deep thoughtfulness while one is working for example, or it can refer to some mental inactivity. One may see someone involved in deep contemplation focusing on a task to the extent that s/he cannot notice people nearby, as opposed to someone who is totally busy either in a day-dreaming or clueless state.

\section{Jakobson's (1960) Communicative Functions}

Investigates the role of silence in Jakobson's (1960) classic model of the communicative functions of language, Ephrat (2008: 1909) highlights the 'eloquent silence' as a means to achieve Jakobson's communicative functions. This model has become becomes well-established in linguistics and many other domains as it concentrates on the following functions:

\section{The Referential Function}

The main purpose of the whole process of communication, whether face-to-face or channeled and whether formal, or informal, is the transmission of information. Language helps its interlocutors send propositions, ideas, or facts about the world to one another.

\section{The Emotive Function}

For Jakobson, (1960: 354 in Jensen:1973), the self-reference made by the use of 'I': in expressions like "I now feel" (Hence, "I feel happy"; "I (am) Ø happy", is an expression of emotions that aims at directly expressing the addresser's viewpoint on the topic under addressing. It is an impression of certain emotions whether true or feigned.

\section{The Conative Function}

For Jakobson (1960: 355), the conative function of language focuses on the 'speech of silence'; it is the silence that motivates the addressee to go on in the normal course of conversing. Having the addressee as the aim in this function, the conative function is grammatically reflected in the use of the vocative and imperative moods of language (ibid.). Hence, Unlike the referential function, silence here does not serve some true-or-false assertions about a third-person outside world because it is in itself a speech act. A good example of this type of speech acts is the procedural silence where silence is a discourse marker, as shown by Sacks et al. (1974), used to be the simplest systematic marker in the organization of turn-taking in particular conversations.

\section{The Phatic Function}

Opposed to the above mentioned three functions which depend on the outside inner and outer world, the phatic communicative function may have some messages that basically help establish, prolong, or cut the flow of communication, and check whether the channel works or not. So, expressions like 'Hello, do you hear me?' has no real communicative function but it is used to make sure that the process of communication is still in action. Jakobson says that this function of language is the only one that animals share with human beings. It is also a verbal function infant acquire earlier in their lives.

\section{Jaworski's (2006) Function of Silence}

Following Halliday's (1978) view of semiotic systems, Jaworski (2006:944) thinks that silence can fulfill three major linguistic functions:

The ideational function, for Jaworski (ibid.), means to hide information. However, it can also show ideational inferences to be made while describing or referring to the non-linguistic reality, as in the case when a silent answer follows a request for informing, e.g.:

A: Who ate all the cookies?

B: [silence].

A: I knew you did! (ibid).

The Interpersonal function means silence, just like any other form of nonverbal communication e.g., can serves ranking the social actors' relations of power and solidarity. Silence here may reflect interpersonal intimacy or extreme distance in contexts where 'small talk' is normally to occur between casual acquaintances (Jaworski, 2000); it, further, can signify extreme power differentials among the participants. 
The textual function refers, for Duez (19820 in Jaworski, 2006), to the organization of coherence, or the definition of the talk frame where pauses can normally be employed to add emphasis to the message. According to Bauman (1997: in Jaworski, 2006), such organizations or frames may precede or occur within a stretch of talk to mark a better performance, as in the case of reciting a poem.

\section{Silence at Linguistic Levels \\ Silence, Phonetics, and Grammar}

Opposition between something and nothing is significant in language and mostly any linguistic analysis is satisfied with the presence versus the absence of linguistic signs. One can say that if the presence of linguistic signs is unmarked, the absence of linguistic signs must be marked. Silence, apparently, can be studied in a more or less explicit way in the most functionally oriented frameworks of linguistic analysis at different levels (Jaworski, 2006: 945). So, Phonetic articulation, for example, organizes itself in the alternation between active and passive, or at rest, speech organs. Similarly, in phonology, any distinctive feature is binary comparison of plus/minus features each of which has its own significance at that level of analysis. Morphology, in its turn, identifies empty elements as zero signs (Jakobson 1971: 212); zero allomorphs and zero allophones can be systematically opposed to other signs.

\section{Silence , Pragmatics and Rhetoric}

In addition to utterances characterizing speech acts, silences in most cases are pragmatically considered meaningful as silence itself functions as an indirect speech act that heavily relies on the context that determines its proposition. For Coulthard and Brazil (1992:77), one of the ways a child can reflect his annoyance at being asked/told to do something, for instance, is by doing that kind of action in silence without any acknowledgement.

While silence or 'holding on' can be understood as an acceptance (ibid.:148), Roben (2005: 206) states that conversation analytic studies have repeatedly shown that silences following requests or invitations are routinely interpreted as indicating refusals or declining:

- MP: Are you coming with me then.

$-(0.5)$

- MP: Do you dare to come (ibid.).

The caller, in this example, pursues the girl's acceptance of the invitation but this is treated with a short silence. The absence of an instant response here is treated as rejection implicative in that the caller asks again for an acceptance, but this time with a different way: the invitation to go for a ride is a kind of a daring idea. Being used here as motivation clue, the reformulation apparently looks like an appeal to a sense of revolution and adventure that is normally associated with teenager.

\section{Silence in Argumentation}

From an argumentation point of view, a silence or absence of comment can be interpreted in many different and quite opposite ways. Peters (2004: 194) highlights the significance of silence among people who tend to use the argument from silence, Latin argumentum ex silentio, and try to win the debate over their opponents just by showing that since that opponent keeps silent, then they agree (ibid.). The main point to be exploited here is that an author/document only keeps silent on certain issue because they are interested in it; then they use the lack or absence of any comment in order to support their stand in the case under debate and to have its own advantage or "bolster their own case". Some other times, silence could be understood as a type of rhetoric that meets the principle of : "heads I win, tails you lose"(ibid).

\section{Silence in Spoken and Written Discourse}

In discourse analysis, some absences of, and pauses in, speech can be used to show prosodic units boundaries the speakers use. Such short silences may be a result of stuttering and stammering, selfcorrection, hesitation, or an intended slowing of speech for purposes of clarification of ideas (Sacks et al., 1974: 704-7; Levinson, 1983: 321). Some longer pauses, however, can be found in other language interactive roles, turn-taking, and/or reactive tokens. These Intervals or silences can be used interactively to arrange the right to talk and the role of those who have the floor or not. In this sense, silence represents the inner limits of discourse and conversation (ibid). Besides, "various versions of Critical Discourse Analysis have focused on silence and silencing as forms of sociopolitical control and oppression" (Jaworski: 2006).

In conversation Analysis, the aim is to explicate the role of silences and its interruptions in the process of interaction (Schroder, 2006: 587). Huckin's (2005 in Flowerdew, 2008: 201) suggests several tools and concepts that critical discourse analysis may including 'textual silences which is defined by 
Jager (2001: 55-6 in Flowerdew, ibid :202) to be a set of categories that represent part of what he calls 'little toolbox for conducting analysis. Silence is assigned different significance by conversation analysts depending on such factors as silence's length and its place to occurs in a conversation (Levinson, 1983: 298). Brown and Yule (1987 : 162), hence, classify pauses according to length into: short pauses ranging from 0.1- 0.6 seconds, long pauses ranging from 1.0-1.9 seconds, and extended pauses extending from 3.2 to 16 seconds. For them (ibid.) pauses units are related to information units as the speakers make use of time to compose their following utterance.

\section{Pinter's Silence}

It is worth mentioning that Pinter's (1957) The Dumb Waiter represents the beginnings of Pinter's dramatist career and his typical style of writing as one of the prominent figures of the Theatre of the Absurd in the 20th century. The play presents the relationship between the killers. They face the problem of communication. They don't trust each other and the last part of the play presents them as a killer and a victim. The mysterious atmosphere of "The Dumb Waiter" is absent in this play. But ambiguity persists as the characters do not reveal well-defined motives. Memory, fantasy and search for the inner self give this play a lyrical touch (Lumley,1973: 271)

Usually, Pinter's pauses as well as silences are the climaxes of the plays, the quiet focus of the storm, the centre of tension around which the whole action evolves (Esslin,1970: 242). Pinter's plays imply skepticism about the power of language to express reality. Many of Pinter's critics explore the role of silence in the menacing tone of his plays, but suggest that Pinter's silences signal not so much a failure of language as a refusal to use language to communicate (Esslin, 1987: 238-9).

The pause and the silence can take on an expository and develop-mental function. Wardhaugh (2006: 243) explains that silence can be used as a kind of sympathizing device after the death of someone. People are silent in the presence of 'people who are sad,' as one should not further disturb those who are already disturbed by deep grief. In addition, silence is required during curing ceremonials when someone is not to be considered disrespectful or to be interfering either with the curing process or with the person conducting the ceremonial.

\section{Data Analysis}

Pinter's (1957) The Dumb Waiter revolves around two assassins live in a basement waiting for their master's(Wilson) orders. One of them is submissive(Gus),whereas the other(Ben) is domineering. Gus keeps on asking questions and complaining about their life. He may keep silent when he feels the tension goes up or hears the threat.Ben either avoids answering or threatens him verbally or by using silence.

The linguistic functions of silence(ideational, interpersonal and textual) presented by Halliday (Jaworski, 2006:644) are the main concern in this study. Regarding the play The Dumb Waiter , conversational turns in the play are enumerated for the easiness of searching for a turn.Thus, the first turn is given number one for example. Texts cited are presented first,then, the discussion of such a text follows.

\section{Text 1.}

44.Gus What time is he get in touch?

(Ben reads)

\section{Discussion}

In this extract, Ben's silence reflects his reluctance to answer. The idea of disfavoured question is shown by employing silence and engagement in doing something else which is reading a newspaper. Thus , ideational function of silence comes to work.

\section{Text 2.}

240 -Gus What does the gas-?

241-Ben (Grabbing him with two hands by the throat at arm's length) THE KETTLE ,YOU FOOL!

(Gus takes the hands from his throat).

242-Gus All right, all right(pause).

\section{Discussion}

Ben interrupts Gus's conversation by threatening him to be harmed physically. It is a covered way of a threat (I will beat or even kill you if you keep on asking or correcting my expressions). The tension is obvious here and Gus is shown as submissive by his final silence . "Power" which is associated with Ben, makes Gus silent. Hence, the distance between the two partners is quite clear. 


\section{Text 3.}

493 Ben (savagely) That's enough .I'm warning you.

(silence)Beb hangs the tube. He goes to his bed and lies down. He picks up his paper and reads.(silence)The box goes up.They turn quickly. Their eyes meet.Ben turns to his paper. Slowly Gus goes back to his bed, and sits.The hatch falls back into place Silence. Ben throws his paper down).

\section{Discussion}

In this text, there is no silence, but it causes silence. Four silences are found in the stage direction that follows. Then, even Ben's speech which follows is evasive as it is an attempt to change the subject or topic they were talking about. Distance, which is one of indications of interpersonal function of silence, is reflected in the lack of communication as well as tension.

\section{Text 4.}

264 Gus (At length)Who it is going to be.(Silence).

265 Are you feeling alright?

266 Sure.

267 Go and make the tea.

268 Yes, sure.

\section{Discussion}

After asking about the new victim twice ,Gus gets no answer. He says (at length) that he wants an answer. Hearing that, Ben threatens him indirectly as if is saying that he would be crazy to ask such a question. It is an attempt of suppressing Gus who obeys the order of changing the topic by going to make tea. Linguistically speaking, the concepts of 'power' and 'distance' are evidently present in such a text .Thus, silence serves the interpersonal function.

\section{Text 5.}

324 Gus Well, WHO'S GOT IT NOW?(silence).

334 Ben What do you mean, who's got it now?

335 Gus Who's got it now ?If they moved out who moved in?

\section{Discussion}

Gus inquires about persons who will move in before presenting this speech. As he has not got any clear answer, he resorts to repeating his question directly followed by a silence to add emphasis that attracts his partner's attention; this silence is maintained by Pinter's capital letters. Such a silence enriches the text, as well as conversation, with emphasis. Hence, the textual function is better reflected.

\section{Text 6}

290 Gus There are a number of things I want to ask him.(Pause).But I can never get round to it, when I see him .(Pause)I've been thinking about the last one.

291 Ben What last one?

292 Gus The girl.

\section{Discussion}

The pause, here, denotes the reason Gus wants to talk to Wilson. He deeply thinks about the last victim the murderer killed. It was a girl. Such a pause reflects coherence in the text as it relates what comes to what precedes. Consequently, it serves the textual function.

\section{CONCLUSIONS}

1. Though silence means a total lack of audible sound, it is in no way related to absolute absence of communication. It is self-evident that studying silence is so significance that it inters into the various domains and different levels of linguistics.

2. Unmarked speech and marked silence are what identifies a certain talk with organized communicative functions of silence and classify them in different ways.

3. Apparently, Pinter in The Dumb Waiter has employed Jaworski's (2006) three functions of silence. However, the most employed one is the interpersonal function as it reflects the 'power' of one of the characters over the other and shows the 'distance' between them. . 
4. Pinter's comedy of menance is constructed the domineering character, Ben, either chooses to be silent to threaten his companion, or cause the submissive one, Gus, to be silent.

5. The study has proved that silence has the same significance and functions of language and that its study in literature in general, and drama in specific, adds so much to interpreting, understanding and teaching literature.

It is, hence, has been concluded that the lack of spoken language does not mean lack of communication receiving or delivering messages, a great deal of silence is employed in speech and written texts to for the sake of communication, and that silence has certain communicative functions in Pinter's The Dumb Waiter. This has verified the three hypotheses of the present study.

\section{REFERENCES}

Brown, G. and Yule, G.(1987). Discourse Analysis. Cambridge: Cambridge University Press.

Coulthard, M. and Brazil, D.(1992) "Exchange Structure" in Malcolm Coulthard (ed.) Advances in Spoken Discourse Analysis. London : Routledge.

Esslin, M.(1970)"Language and Silence," in Martin Esslin The Peopled Wound. Doubleday :Martin Esslin, pp. 207-42

Esslin, M.(1987) "Language and Silence." in Harold Bloom (Ed.) Harold Pinter. New York: Chelsea House PP-139-63.

Fairclough, N. (2015). Language and power. (3rd Ed.). London: Routledge.

Flowerdew, J.(2008)"Critical Discourse Analysis and Strategies of Resistance" in Vijay K. Bhatia, John Flowerdew and Rodney H. Jones (ed.)Advances in Discourse Studies. 195-21. London :Routledge.

Jakobson, Roman (1971). "Signe zero". In: Selected Writings II. Paris: The Hague PP- 211-219.

Jaworski, A.(2006) "Silence" in Jacob Mey (ed.) Concise Encyclopedia of Pragmatics PP- 644-645.

Jensen, V.(1973)“Communicative Functions of Silence.” In ETC Journal. Vol. 30,PP- 249-257.

Kurzon, D.(2006) "Law and Language: Overview". in Jacob Mey (ed.)Concise Encyclopedia of Pragmatics .PP 510-513.

Levinson, S. (1983). Pragmatics. Cambridge: Cambridge University Press.

Lumley, Fredric (1973) Trends in 20th Century Drama. London: Barrie and Jenkins Ltd.

McHoul, A. (2006)"Discourse, Foucauldian Approach" in Jacob Mey (ed.) Concise Encyclopedia of Pragmatics PP- 201-206.

Nakane, I. (2014). Interpreter- mediated police interviews: A discourse- pragmatic approach. New York: Palgrave.

Paulston, C. B., Kiesling, S. F., \& Rangel, E. S. (Eds.). (2012). The handbook of intercultural discourse and communication. Malden, Mass.: Wiley-Blackwell.

Peters, P.( 2004 )The Cambridge Guide to English Usage .Cambridge :Cambridge University Press .

Roben, R.(2005)Conversation Analysis and Discourse Analysis:A Comparative and Critical Introduction .London: SAGE Publications

Sacks, H., Schegloff, E., \& Jefferson, G. (1974). "A Simplest Systematics for the Organization of Turn Taking in Conversation". Language, 50, 696-735.

Schegloff, E. (2001)" Discourse as an Interactional Achievement III: The Omni Relevance of Action" in Deborah Schiffrin, Deborah Tannen,and Heidi E. Hamilton (ed.)The Handbook of Discourse Analysis .PP-229-249.0xford: Blackwell Publishers Ltd.

Schroder, K.(2006). "Media: Pragmatics". in Jacob Mey (ed.) Concise Encyclopedia of Pragmatics .PP 584592.

Wardhaugh, R.(2006) An Introduction to Sociolinguistics (5th ed.).Australia: Ronald Wardhaugh. Blackwell Publishing.

A. J. Obaid and S. Sharma (2020), "Recent Trends and Development of Heuristic Artificial Intelligence Approach in Mechanical System and Engineering Product Design," Saudi Journal of Engineering and Technology, vol. 5, no. 2, pp. 86-93. 